\title{
Strategies for Field Management Using RFID Technology in Nuclear Plants
}

\author{
Hyun Chan Lee \\ Industrial Engineering Department, Hongik University, \\ Seoul, Republic of Korea
}

\begin{abstract}
In this paper, we propose new strategies to manage bulk material inventory in plant yard using RFID(Radio Frequency IDentification) technology. In the new strategies, we subdivide the field inventory area into cells to be coved by RFID readers. Each cell is covered by a RFID reader to keep tracking the current inventory of the bulk materials. The proposed method can be used any kind of plants. The strategy is proposed to Korean Nuclear plants.
\end{abstract}

\section{Keywords}

RFID, field management, bulk material inventory, nuclear plant, area subdivision.

\section{INTRODUCTION}

RFID(Radio Frequency IDentification) technology is a wireless technology to store and retrieve information in a tag form. The tagged RFID chips can store certain amount of information to be used later. The product information can be stored in the chip, and the information is used for various activities to manage the product. The activities include inventory management, remote control, information exchange, etc. [1]

The RFID technology has replaced the bar or QR code technology in some business areas, such as material management, information networking, logistics, SCM(Supply Chain Management), etc. The application areas of the RFID are ever expanding in business. Many new business models are developed using RFID technology. [2]

The RFID technology has powerful functions of updating information stored, which the bar or QR code technology does not has. By actively updating the information in the RFID chips, business areas such as logistics, SCM, security, and inventory management can become much more efficient. The following are the major characteristics of RFID technology.

- RFID technology is a wireless automatic data identification technology using radio frequency.

- The information is stored in or retrieved from a RFID chip using wireless radio frequency. No physical touch is required.

- $\quad$ An ID(IDentification) is assigned to each tag and reader and antenna are used to access or store the information of the RFID chip.

The data model associated with the RFID is given in Figure 1. The data model is used in the information system to manage nuclear plants in Korea. [7-11] The data model includes geometric and non-geometric properties of equipment. Selected data on the equipment is stored in the RFID with product number. The RFID is attached to the equipment. Mobile readers of the RFID scan the information whenever necessary and verify the information data against the company warehouse through wireless network.

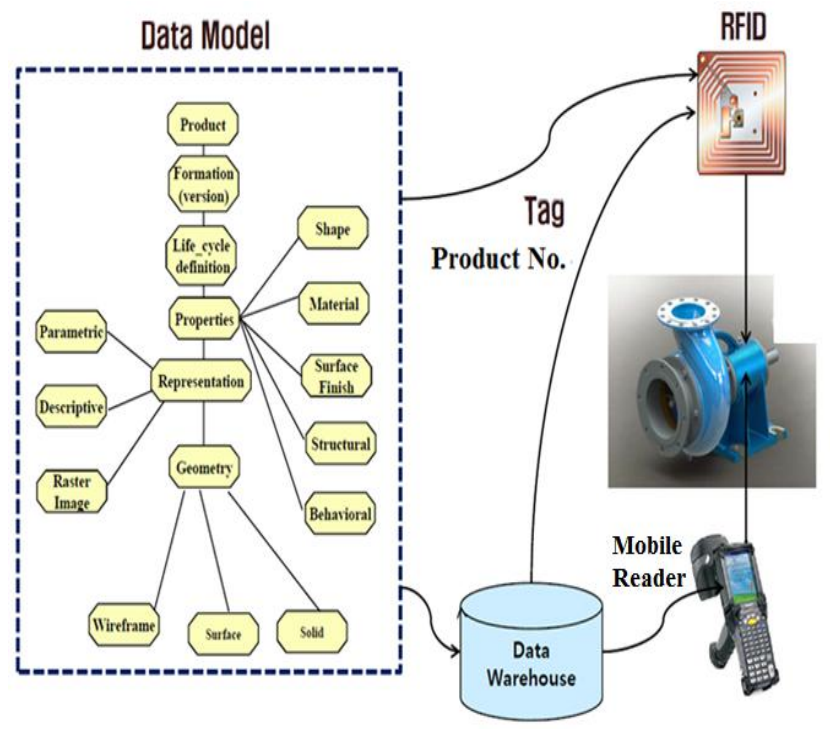

Figure 1. Data model associated with the RFID

The RFID tag system configuration is given in Figure 2. In the figure, mobile (smart phone) reader/writer is the center of the system to control the information in the target (tag) systems. The mobile device store and access the target systems to support the information management activities. The mobile device also accesses the system sever through RFID server to verify the accuracy of the information in the target systems.

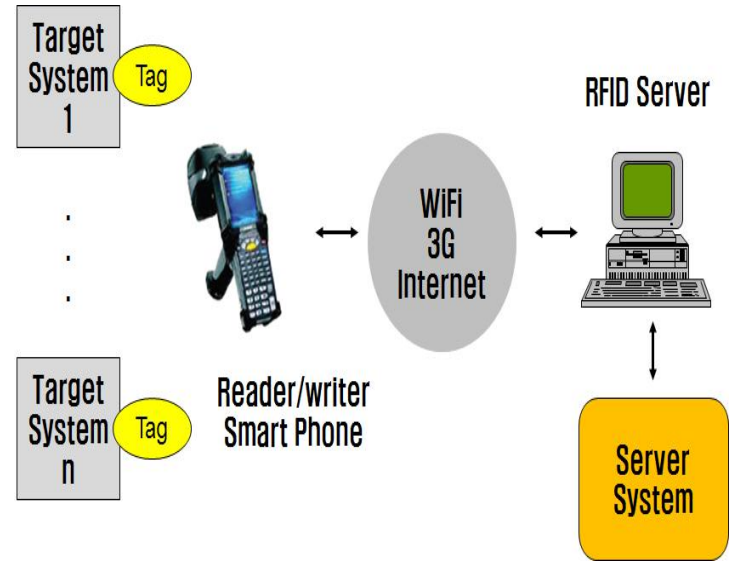

Figure 2. RFID tag system configuration 
The sequence the activities for operating the RFID tag system is given in Figure 3. The sequence is given in 8 steps as follows:

1. The data requested in the tag is transmitted to the reader

2. The mobile reader receives the transmitted data.

3. The reader sends the data to server PC.

4. The server $\mathrm{PC}$ receives the data.

5. The server PC transforms the data.

6. The transformed data is ready to be exported.

7. The exported data is sent to enterprise applications

8. The applications receive the requested data.

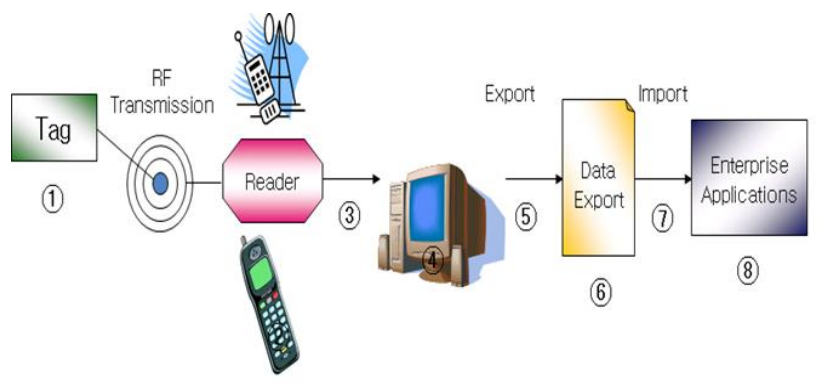

Figure 3. Operating sequence of the RFID tag system

In this paper, we summarize the related RFID technology case in Section 2. In Section 3, we analyze the currently used systems and give reasons for using RFID technology. In Section 4, we propose the area subdivision and dynamic systems for bulk materials inventory management. Then, we conclude and discuss future researches.

\section{RELATED RFID TECHNOLOGY CASE}

In the most of the current bulk inventory yard, RFID readers are located at the entrance of the yard. The readers identify the individual item, box, palette, etc. to record the flow of bulk materials inventory. In this case, the amount of the flow is identified at the entrance only. Therefore the loss of materials in the yard due to theft, corrosion, etc. cannot be traced.

The single entrance recognition system is implemented by Fiatech in the project titled "Field Trials RFID Technology for Tracking Fabricated Pipe - Phase II." [4] In the project RFID tags are attached to pipe as shown in Figure 4.The tagged pipes are loaded in a truck and go through doorway RFID readers as given in Figure 5. Identified amount of the pipes are automatically recorded in the RFID server and update the level of inventory.

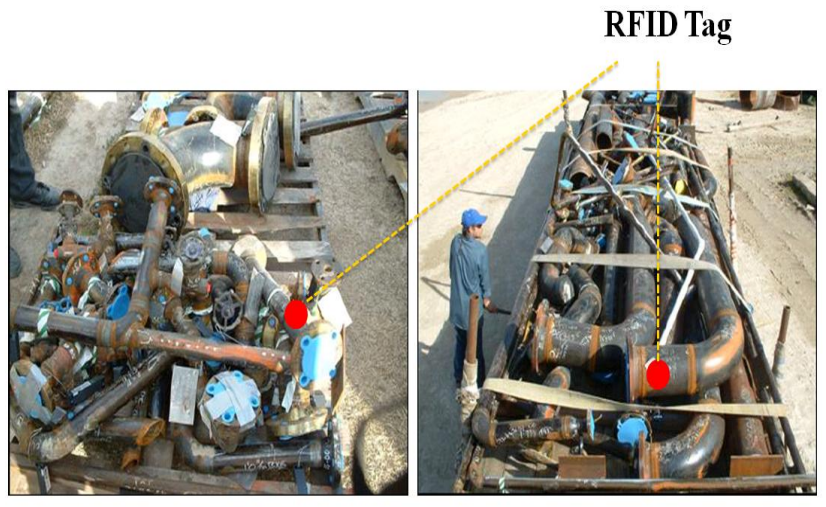

Figure 4. RFID tag attached to pipe

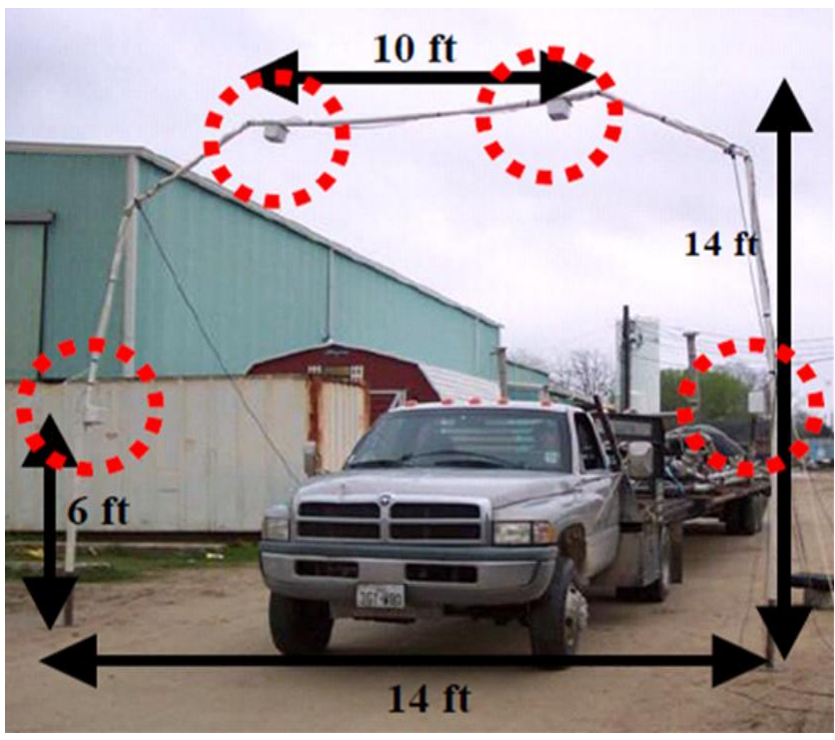

Figure 5. Four RFID readers installed at the doorway

In the Fiatech project, RFID functions are tested and the results are given in the Table 1. They examine three types of the RFID readers such as i-D and i-Q tags, and i-Port III reader. An example of the I-Port III reader is given in Figure 6 and the major properties of the reader is as follows:

$$
\begin{aligned}
& \text { - } \quad \text { Identification } \\
& \text { - } \quad \text { Tracking and tracing localization } \\
& \text { - } \quad \text { Multi-tag compatibility } \\
& \text { - } \quad \text { Concurrent antenna processing } \\
& \text { - } \quad 100 \mathrm{tag} / \mathrm{s} \text { identification rate } \\
& \text { - } \quad 2,000 \mathrm{tag} \text { simultaneous identification } \\
& \text { - } \quad \text { Real-time operating system (RTOS) } \\
& \text { - } \quad \text { Remote diagnostic and configuration }
\end{aligned}
$$

Table 1. Results of RFID function test

\begin{tabular}{|c|c|c|c|}
\hline $\begin{array}{c}\text { Tag / } \\
\text { Reader }\end{array}$ & $\begin{array}{c}\text { Active } \\
\text { frequency }\end{array}$ & $\begin{array}{c}\text { Maximum range } \\
\text { of recognition }\end{array}$ & memory \\
\hline i-D Tag & $915 \mathrm{MHz}$ & $20 \mathrm{ft}$ & 64 Byte \\
\hline i-Q Tag & $915 \mathrm{MHz}$ & $300 \mathrm{ft}$ & $32 \mathrm{~KB}$ \\
\hline $\begin{array}{c}\text { i-Port III } \\
\text { Reader }\end{array}$ & $915 \mathrm{MHz}$ & $\begin{array}{c}20 \mathrm{ft} \mathrm{w} / \mathrm{i}-\mathrm{D}, \\
300 \mathrm{fr} \text { wi-Q }\end{array}$ & \\
\hline
\end{tabular}

An example of an i-Q series tag is given in Figure 7. One of the powerful tag in $\mathrm{i}-\mathrm{Q}$ series is I-Q8 tag, which uses UHF frequency and recognizable in maximum range of $300 \mathrm{ft}$. The detail specification of the tag $\mathrm{i}-\mathrm{Q} 8$ is given in Table 2. The characteristics of $\mathrm{i}-\mathrm{Q}$ series tag is as follows:

- Identification

- $\quad$ Tracking and tracing 
- Localization monitoring

- Temperature monitoring

- $\quad$ ILR(Intelligent Long Range) active RFID Tag

- 100 meters Read/Write range

- 100 tags/sec.

- 2,000 tags simultaneous identification

- Temperature logging

- LED

- 6 year battery lifetime

- Low Cost

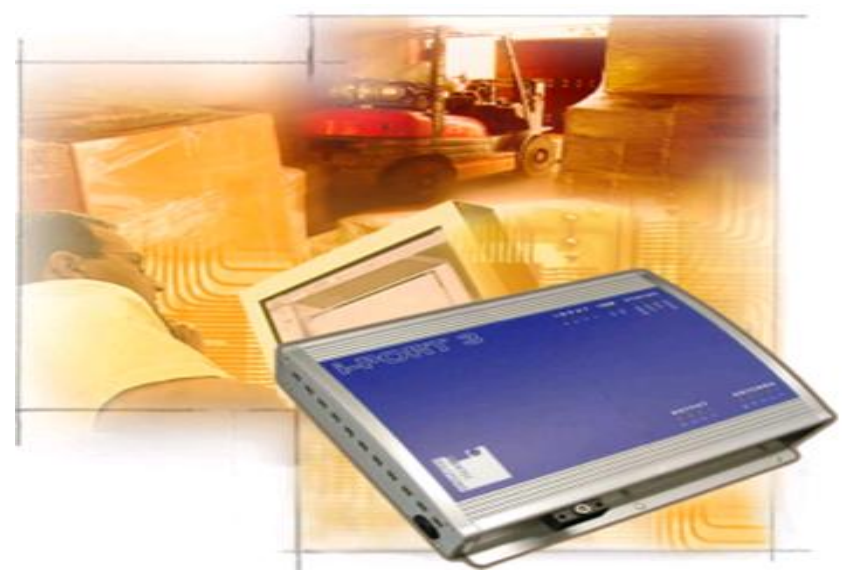

Figure 6. Fixed UHF interrogator I-Port III reader

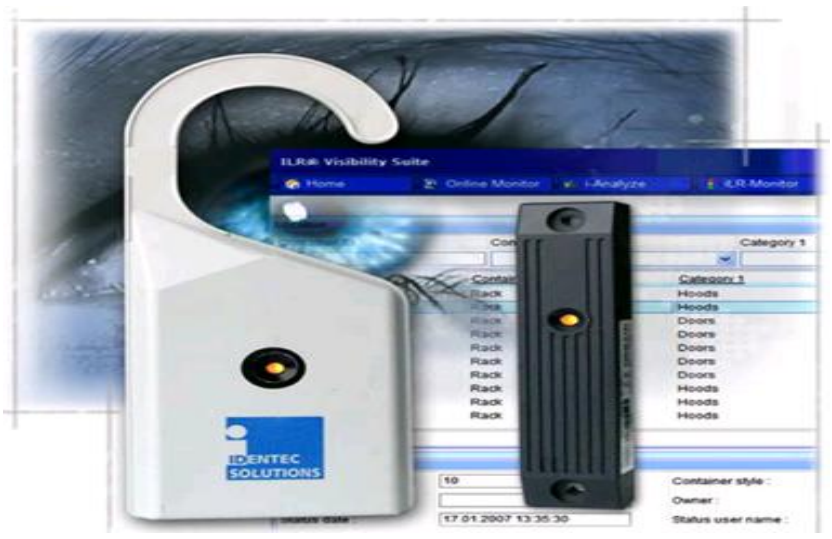

Figure 7. Active UHF tag I-Q series tag

Table 2. I-Q8 tag technical specifications

\begin{tabular}{|c|c|}
\hline Active frequency & UHF (868 MHz or 915 MHz) \\
\hline Reading distance & Maximum 300 ft Read/Write \\
\hline Standard/Certification & $\begin{array}{c}\text { EN } 300200 \text { (EC), FCC Part 15 (US), } \\
\text { Industry Canada }\end{array}$ \\
\hline Memory size & $8 \mathrm{~Kb}$ \\
\hline Operating temperature & $-40^{\circ} \mathrm{F} \sim+158^{\circ} \mathrm{F}$ \\
\hline \multicolumn{2}{|c|}{ Temperature recording / visual identification functions (LED light) } \\
\hline
\end{tabular}

The listed three RFID technologies in Table 1 are tested by Fiatech how efficient they are. The first test results are given in Table 3. There is a good possibility that an i-Port III can be used in moving situation. Table 4 also shows tags i-D and i-Q series mentioned above can be reliably used in the moving situation.

\section{Table 3. Test results I}

\begin{tabular}{|c|c|c|c|c|c|}
\hline Item & $\begin{array}{c}\text { \# of } \\
\text { Tagged } \\
\text { Spools }\end{array}$ & $\begin{array}{c}\text { Total } \\
\text { Passes }\end{array}$ & $\begin{array}{c}\text { Number of passes in which } \\
\% \text { range of tags were read }\end{array}$ \\
\hline 1 & 82 & 13 & 6 & 6 & 1 \\
\hline $2-A$ & 50 & 2 & 0 & 0 & 2 \\
\hline $2-B$ & 50 & 18 & 6 & 10 & 5 \\
\hline $3-A$ & 56 & 9 & 6 & 1 & 2 \\
\hline $3-B$ & 56 & 11 & 4 & 6 & 1 \\
\hline $3-C$ & 56 & 16 & 15 & 1 & 0 \\
\hline
\end{tabular}

Table 4. Test results II

\begin{tabular}{|c|c|c|c|c|c|}
\hline $\begin{array}{c}\text { Test Bed } \\
\text { NO. }\end{array}$ & $\begin{array}{c}\text { NO. \& } \\
\text { Type of } \\
\text { Tags }\end{array}$ & $\begin{array}{c}\text { NO. of } \\
\text { Trips }\end{array}$ & $\begin{array}{c}\text { Mean } \\
\text { Read } \\
\text { Rate }\end{array}$ & $\begin{array}{c}\text { Median } \\
\text { Read } \\
\text { Rate }\end{array}$ & $\begin{array}{c}\text { Duplicate } \\
\text { Read } \\
\text { Ratio }\end{array}$ \\
\hline 1 & $\begin{array}{c}83 \text { i-Q } \\
\text { tags }\end{array}$ & 12 & $98.1 \%$ & $98.8 \%$ & 1.4 \\
\hline 2 & $\begin{array}{c}50 \text { i-D } \\
\text { tags }\end{array}$ & 20 & $96.4 \%$ & $98.0 \%$ & 1.9 \\
\hline 3 & $\begin{array}{c}56 \text { i-Q } \\
\text { tags }\end{array}$ & 38 & $96.0 \%$ & $100.0 \%$ & 6.8 \\
\hline
\end{tabular}

\section{FIELD ANALYSIS}

To suggest effective field management strategies, we analyze the currently used methods. The analysis leads us to the new ways of doing.

\subsection{Hand Written Code}

Some field area, hand written codes are still used. Figure 8 is an example of the hand written code. The figure shows the hand written codes can be unreadable as time passed by. More advanced technology is needed to manage field area.

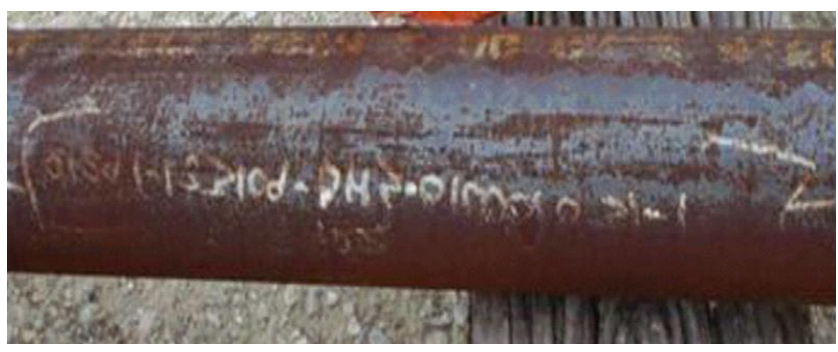

Figure 8. Readability problem of hand written code

\subsection{Bar Code}

To cope with the readability problem of the hand written code, most of the company uses bar code in the field management. When new boxes or items are placed in or removed from the storage field, the bar codes are used to count the volume and 
record the results. However the size of the facilities of the plant can be very large to use bar code. Depending on the location of the bar code attached, field worker cannot find the bar code, which results in the inaccuracy of the record. Therefore bar code can be inefficient in open field management. The Fiatech RFID implementation strategy is the new way to adapt in field management.

\section{PROPOSED STRATEGIES}

In Section 2, we explained Fiatech project. In the project, the main idea is to place the RFID reader at the entry of the inventory field area to control the bulk materials. The idea is illustrated in Figure 9. Only read the in and out of the materials using RFID attached to the materials at the entry. In Figure 9, the number indicates the different kind of materials. Each number corresponds to specific material prespecified.

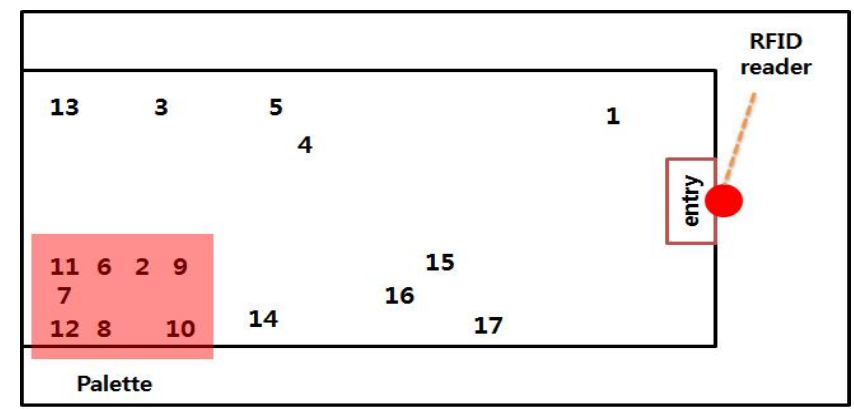

Figure 9. Entry reader (Fiatech Project) [3]

In this case, as time goes by, the location of the bulk materials stored are not clear, therefore as given in Figure 10 field worker has to identify the bulk materials to verify the record in the server at the end of fiscal year or whenever necessary. This kind of problem arises when the amount of bulk materials is huge or the storage time is long.

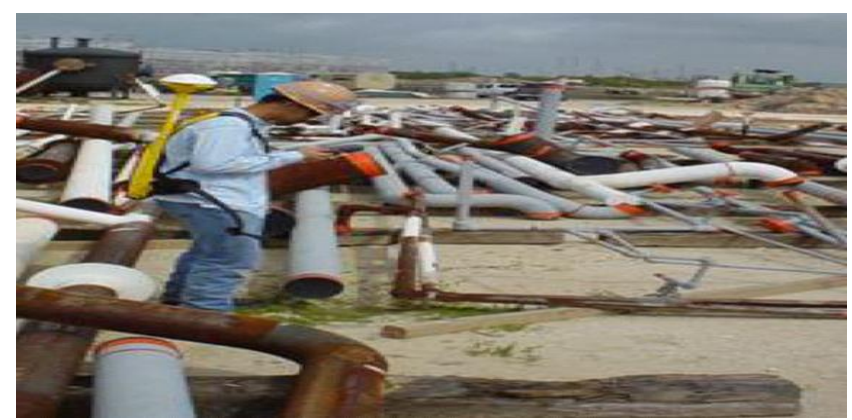

Figure 10. Identified by the field worker

To remove human intervention in verifying the record in the server, we proposed cell based area covering. In the cell based area covering, many RFID readers are required as given in Figure 11. The red circle indicates the location of RFID readers. In addition the entry RFID reader, six more RFID readers are positioned in the field area. The number of RFID readers to be added depends on the capacity of the reader. The more the reader is powerful, the less number of readers is required.

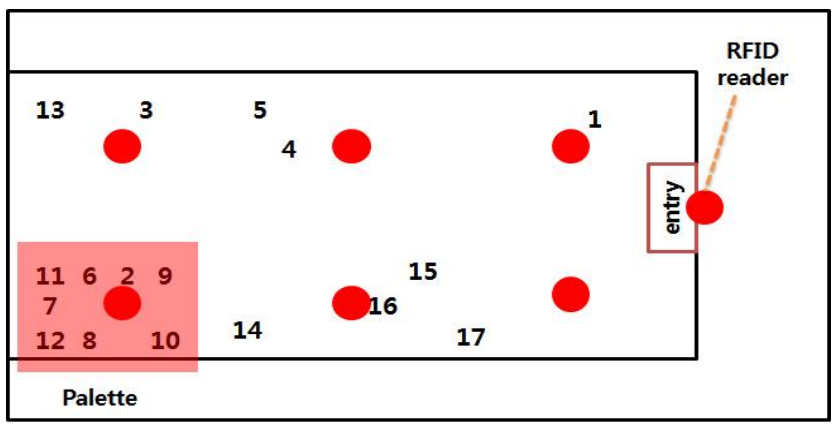

Figure 11. Cell covering readers (proposed strategy)

A method to calculate the number of readers to be located in the field area is illustrated in Figure 12. In the figure, we assume that a reader can recognize the area of a circle with radius $90 \mathrm{~m}$. To cope with the circular shape of the coverage, we need 8 cells to each direction, which results in $8 \times 8=64$ cells to cover $1 \mathrm{Km} x$ $1 \mathrm{Km}$ field area. In this case, we minimize the duplicate coverage by the multiple cell readers.

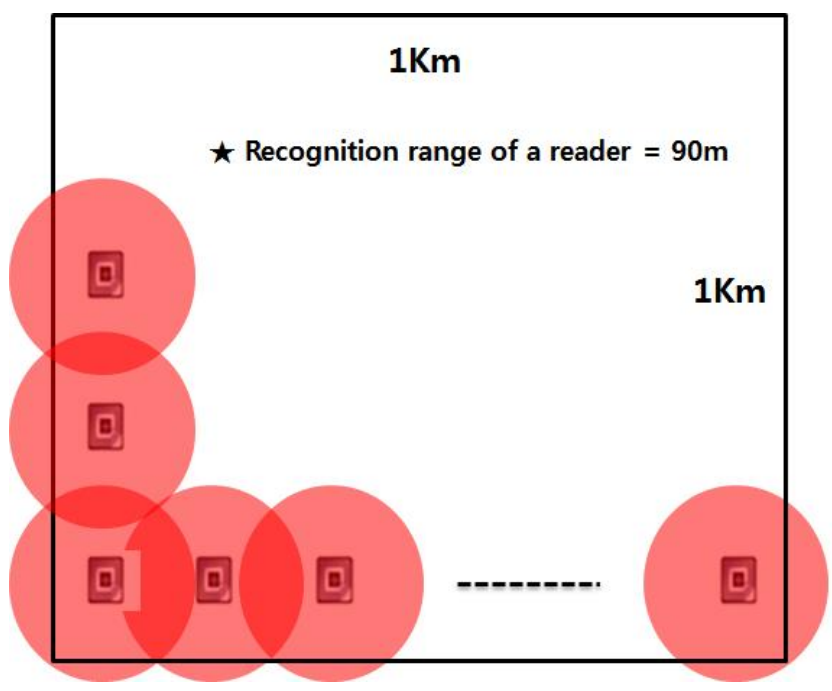

Figure 12. Cell covering readers positioning

In this strategy, we need the following sequence of automated processes. In this case, we continuously monitor the field using cell readers instead of the field worker as given in Figure 13.

1. A tag is attached to a bulk of materials inspected

2. The bulk is loaded to a truck or trailer

3. Identify the tag using the entry reader

4. Record the tag data into server

5. Locate the bulk materials in the field yard at the prespecified cell

6. Cell readers are used to identify the bulk materials whenever required 

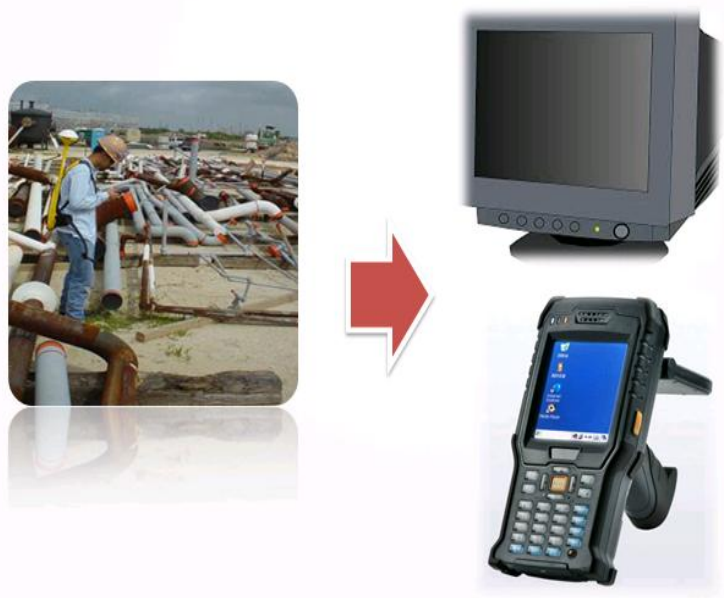

Figure 13. Management through the monitoring

The proposed strategy needs initial investment to install multiple cell readers. However the proposed has a lot of advantages in field inventory management as listed below.

- Proper inventory level is maintained by real time identification of the inventory

- $\quad$ Reduction of the field workers

- $\quad$ Prevent theft and losses

- Cost and time reduction by removing hand working

More dynamic strategy can be implemented using mobile readers or moving readers attached at drones as given in Figure 14. The dynamic strategies can be used when the yard area is too wide to used fixed cell readers. In this case the scanning strategy using the dynamic readers has to be well designed to cover all the area.

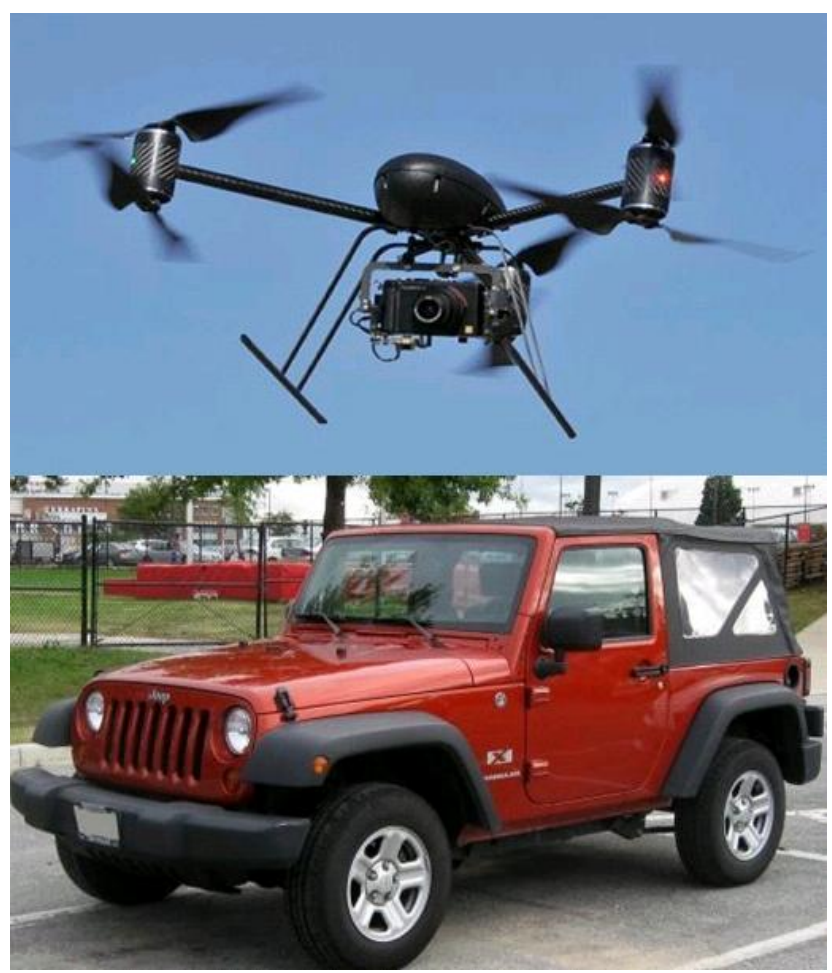

Figure 14. In the form of removable reader

\section{CONCLUSION}

In this paper, we propose new strategies to manage bulk material inventory in plant yard using RFID technology. In the new strategies, we subdivide the field inventory area into cells to be coved by RFID readers. Each cell is covered by a RFID reader to keep tracking the current inventory of the bulk materials. The proposed method can be used any kind of plants. The strategy is proposed to Korean Nuclear plants. Dynamic strategies are also proposed. New strategies tremendously reduce the time and cost of the bulk materials inventory management.

\section{ACKNOWLEDGMENTS}

This work was supported by 2014 Hongik University Research Fund.

\section{REFERENCES}

[1] Gwak, B.D., 2011, ECAS(Exhibition Contents Authoring System) and Intelligent Exhibition Space Realization for Media Art Exhibition based on Culture Technology, KISTI(Korea Institute of Science and Technology Information).

[2] Kim, B.G., 2008, Design and implementation of intelligent transport system based on RFID middleware, Hallym Universiry.

[3] Wadephul, J., Wood,C.R., Song, J., Haas, C., Caldas, C., Ergen, E. and Akinci, B., 2004, Field Trials of RFID Technology for Tracking Fabricated Pipe, FIATECH 


\section{Strategies for Field Management Using RFID Technology in Nuclear Plants}

[4] Wadephul, J., Wood,C.R., Song, J., Haas, C., Caldas, C., Ergen, E. and Akinci, B., 2004, Field Trials of RFID Technology for Tracking Fabricated Pipe - Phase II, FIATECH.

[5] IDENTEC SOLUTIONS, www.identecsolutions.com

[6] Jung, F,S., 2007, A Study on the collection of books management using RFID, Kwangwoon University.

[7] Lee, H.C., 2013, Development of Transformation Methods of Nuclear Plant Data Models to International Standard Formats and Development of Management Methods of Facilities, The 1st Mid-term Report, May, KEPCO E\&C, Hongik University (In Korean).

[8] Lee, H.C., 2013, Development of Transformation Methods of Nuclear Plant Data Models to International Standard Formats and Development of Management Methods of Facilities, The 2nd Mid-term Report, November, KEPCO E\&C, Hongik University (In Korean).
[9] Lee, H.C., 2014, Development of Transformation Methods of Nuclear Plant Data Models to International Standard Formats and Development of Management Methods of Facilities, The 3rd Mid-term Report, May, KEPCO E\&C, Hongik University (In Korean).

[10] Lee, H.C., 2014, Development of Transformation Methods of Nuclear Plant Data Models to International Standard Formats and Development of Management Methods of Facilities, The 4th Mid-term Report, November, KEPCO E\&C, Hongik University (In Korean).

[11] Lee, H.C., 2015, Development of Transformation Methods of Nuclear Plant Data Models to International Standard Formats and Development of Management Methods of Facilities, The Final Report, June, KEPCO E\&C, Hongik University (In Korean). 